A CASE IN WHICH HYDATIDS WERE DIS-
CHARGED FROM THE KIDNEY DURING LIFE.

\author{
By E. H. SIEVEKING, M.D., F.R.C.P.,
}

ASSISTANT-PHYSICIAN TO ST. MART'S HOSPITAL.

THE occurrence of hydatids in various organs of the body, and more especially in the liver, is a fact with which those who frequent the dead-house of a hospital are familiar. We do not as often meet with instances of their elimination from the body during life; and when this spontaneous removal is effected, it is commonly with symptoms of very considerable disturbance and previous disorganization. Thus when hydatids form between the lamellæ of a flat bone, as in a most remarkable instance detailed in the tenth volume of the MedicoChirurgical Transactions by Mr. Keate, they induce great enlargement and gradual absorption of the surrounding tissues, until they are thrown off by their matrix, or the nidus is removed by the knife. When they are discharged, as sometimes happens, from the liver, adhesions first form with the parietes, abscesses ensue, and nature thus evacuates the parasite through the abdominal walls. More commonly, however, the hydatid cyst, after attaining a certain size, remains dormant, is borne without suffering, and without exciting any symptoms that attract the attention of the medical man; they are then only made manifest in the post-mortem examination. The independent vitality of the cyst is a fact to which we should not now advert were it not that it appears to have a special bearing upon the case which we are about to relate. This independence is shown both by the anatomical isolation which it maintains in reference to the tissue or organ in which it grows, as well as by a susceptibility of decay and involution, of which the adjoining parts do not partake. Thus we see hydatid sacs converted into what appears to be an encysted abscess, were it not that the microscope reveals their real nature; their contents are a green purilaginous fluid, and there is no symptom of inflammatory action around. The peculiar structure of the cyst, the parallel laminze constituting the membrane, the remains of the echinococci, their fangs, or here and there an entire animal, floating in the corpuscular fluid, easily establish the character of the cyst we have to deal with. The entire absence of bloodvessels in the cyst-membrane, however, militates against the occurrence of anything analogous to inflammation within it. We must therefore seek for another explanation to account for the presence of a purulent fluid in this place. In two cases of this kind that have occurred at St. Mary's Hospital, I found that the contents exhibited under the microscope no traces of pus-an observation the truth of which my friend Dr. Handfield Jones can corroborate. We found granular matter, granular corpuscles, varying much in size and shape but distinct from pus cells, and a large quantity of free oil, the green colour of which communicated to the entire mass its peculiar hue. Many of the larger corpuscles, which all presented a sharp outline, showed oily molecules in their interior. We should therefore infer that here a process of disintegration was going on, the result of which was the production of the granular and fatty matter, in which the cell formations that belong normally to these bodies were partially persistent. We shall see that in the following case a greenish, purulentlooking fluid was evacuated by the urethra; but though, to judge by the microscope, it was almost identical with pus, we may perhaps, upon the strength of the observations just given, and as an inference from the symptoms displayed in the history, conclude that it was rather a result of decomposition within the hydatids, than of the vital action occurring in inflammation. We only premise that the patient was an outpatient at St. Mary's Hospital, and that, as he has not applied for advice since the 29th of July, the cure may be assumed to be permanent.

July 22nd, 1853.-Daniel Larry B-, a brazier and tinker, aged twenty-one, and single, always enjoyed good health until about four weeks ago, when he became affected with gonorrhœa, for which he was treated with a variety of medicines. A fortnight later he was seized with very severe pain in the right hypochondrium, extending to the spine, on the right side of which, about the heads of the eleventh intercostal space, there was considerable tenderness on pressure. The pain was increased by drawing breath; there was also great headache, the tongue was swollen and yellow, the pulse small and feeble, and the cutaneous surface was slightly jaundiced. The patient had lost his appetite, and stated that he had be- come much emaciated; his bowels were open, and there was still a slight trace of the gonorrhoea. He attributed his present malady to a wrench received while playing at skittles. I was inclined to assume the formation of hepatic abscess. I ordered a blister to the painful spot at the back, and the following:-Sesquicarbonate of soda, three drachms; Battley's solution, one drachm and a half; liquor of taraxacum, three ounces; mucilage mixture, nine ounces: a tablespoonful to be taken three times a day; mercury-with-chalk, two grains; compound ipecacuanha powder, eight grains: a powder to be taken every night.

27 th. - He called at my house to show me a mass of jellylike, whitish substance, which, when spread out, closely resembled the wall of an acephalo-cyst; it was irregularly quadrilateral shape, about two inches long by one and a half broad. He had passed it the night before by the urethra, without any difficulty. He has felt much easier since employing the remedies, and his complexion is clearer. His tongue is still furred, but cleaner; pulse 93 . He passed some urine in my presence, which was clear, amber"coloured, with a string of albuminoid matter floating in it: it contained no albumen. $\mathrm{He}$ complained of having for two days suffered pain in the right eye, and the day before an inguinal hernia had occurred on the right side. Examined by the microscope, the membrane exhibited the peculiar laminated appearances of hydatid cysts; a few torulæ were also seen upon it, and some granulated corpuscles like pus that is breaking up. The stringy substance in the urine consisted of what resembled pus corpuscles enveloped in, and held together by an amorphous viscid matter. Rhubarb and magnesia mixture, one ounce, twice a day.

29th.-After he left me on the 27th inst. he passed a large quantity more of the hydatid membranes, and five times he evacuated from the urethra a milky, turbid, puriform fluid, in which no subsidence took place after being allowed to stand The sixth act of micturition brought away clear urine, and normal urine has continued to be passed since. It is, to-day, rather darker than usual, but clear, and contains neither albumen nor sedimentitious matter. He thinks that he passed nearly three half-pints of the milky fluid. He has now no pain in the back, and but little in the right hypochondrium. The tongue is furred; the pulse 88 . He feels generally stronger; in fact, he states himself to be almost as well as ever.

He has throughout experienced no pain in the course of the ureters, bladder, or urethra, and has had no difficulty in evacuating the masses. These are in five large, ragged, and irregularly quadrilateral pieces, four presenting a milky-white, smooth, external surface, and transparent, laminated lining; the fifth, though large, is more transparent than the others, and is evidently only a portion of detached lining membrane. They might be estimated as large enongh to hold an orange if joined together. The milky fluid, after standing, remained a perfect emulsion of a greenish-white hue and acid reaction; it was almost solidified by the application of heat and nitric acid. The membranes, under the microscope, showed the laminated appearance and delicate parallel stria of the hydatid cyst. The inner surface was covered with what closely resembled pus corpuscles, and the débris of animal matter of an irregular form. No echinococci or their remains, such as their fangs, conld be discovered upon the membranes or in the fluid. The latter consisted of well-formed, granular corpuscles, of about $\frac{2}{500}$ ths of an inch, circular, well-defined, and not to be distinguished from pus corpuscles. Among these floated a few larger cells of about $\frac{4}{5000}$ ths of an inch, of a definite, circular outline, and dotted with spherical molecules of oil.

I ordered him a tonic infusion on the 29 th, since which date he has not returned.

In reviewing the brief history of this case, I should be inclined to think that the hydatid cyst, which had necessarily formed long previously, commenced a disintegrating process, at the time when the patient, in consequence of the wrench at skittles, first felt the pain in the back and hypochondrium; that the cyst must have been situated in the vicinity of the renal calyx, and that the pain was owing to the effort of discharging so bulky a mass. The healthy urine that was passed at the time the hydatid was descending, must have come from the left kidney, and from the rapid abatement of the icteric symptoms, and of the headache, after the patient had got rid of the effete membranes, it is fair to assume that they were only sympathetic and not owing to the presence of hydatids in, or to any other idiopathic malady of, the liver. 
Still it is remarkable that the interruption to the functions of a kidney, for a considerable period, and the local disorganization that must have taken place, should have been accompanied by, comparatively, so little disturbance.

Bentinck-street, Manchester-square, Aug. 27, 1853.

\section{ON THE TREATMENT OF BUBO.}

Bт JOHN L. MILTON, Esq., M.R.C.S. Eng.

Ir the reader will turn to The LANoET, March $23, \breve{1} 850$, he will find a paper "On the Use of Tartar-Emetic in Inflammation of the Cellular Tissue." This was followed, in 1850, by a pamphlet on the results of the same treatment applied to Bubo and Perinæal Abscess, with some additional observations on the different modes of treating these inflammatory swellings in various phases of their development. As this paper was brought ont merely for private distribution, its contents must necessarily be unknown to many of my readers, and $I$ therefore purpose, first of all, giving a short sketch of the principles laid down in it, reduced, for the sake of brevity, to the narrowest limits possible.

I there stated my conviction-

1. That bubo in its mildest form is rapidly cured by small blisters.

2. That in the acute form no effort should be spared to obtain resolution, which may in general be readily effected by full doses of tartar-emetic, as one grain ever two or three hours, and the application of very hot water to the bubo.

3. That when resolution is effected, the hardening and engorgement may be removed, as in the indolent bubo, by iodide of potassium, aided by blistering, and the subsequent employment of tincture of iodine, friction, in every form, being injurious and painful.

4. That when resolution cannot be effected, the best plan is to evacuate the pus by means of a needle introduced through the sound skin, or at the lower side of the red halo which points out the seat of inflammation.

5. That when a bubo is not submitted to the surgeon's care till it has burst, it seems better to treat it by irrigating the surface freely with warm water, than by the direct applicacation of stimulants, which are more painful and not so efficient.

6. That absorption of the indolent bubo may generally be effected by the use of tincture of iodine, blisters, and iodide of potassium.

I also directed attention to the facts, that the ordinary modes of procuring resolution frequently fail; that promoting suppuration, where it can be prevented, seems of questionable benefit; that cutting a bubo sometimes fails to check the advance of suppuration, while it has often been followed by the most serious results, and even by loss of life; that burning it with caustic is frightfully painful; and, finally, forming large sloughs, as recommended by Malapert, Cullerier, and

Ricord, is equally barbarous and unscientific.

Such were the opinions I ventured to put forth in the pamphlet I have spoken of, and before the reader has concluded the present article, he will see that I am now labouring to extend and improve this treatment, and striving to force home the conviction that the knife ought to be totally laid aside in these affections.

Let me then call attention to-

$a$. The disadvantages attending the ordinary treatment of bubo, and especially of allowing the air to come in contact with the suppurating cavity;

b. The advantages attending an opposite plan of treatment, more particularly that of drawing off the pus as soon as its presence is detected;

c. And to any objections which have been, or might be urged against this plan.

a. I believe few surgeons will attempt to controvert the statement that the ordinary means of treatment frequently fail in effecting resolution in bubo. I am not the only person who has expressed an unfavourable opinion of their efficacy, and it would be an easy but superfluous task to find in surgical works, arguments not only against the sum total, but even against each separate item of the usual treatment. Now, when resolution cannot be effected a bubo must either burst or be opened.

If the former take place, there is a large suppurating cavity, which takes a long time to fill up again, throwing out for weeks a profuse discharge: a constant source of annoyance and discomfort to the patient, and ending in an ugly scar.

If opened, so as directly to expose the seat of suppuration to the air, it rapidly passes into nearly the same state. The edges of the opening ulcerate till there is a wide gap, entailing the same distressing consequences-suppuration and its attendant filth, confinement for weeks, and an ugly scar.

Should a small opening be made with the view of avoiding unnecessary pain, sinuses almost inevitably result, more particularly if the opening be not made in the lowest part of the swelling. Weeks and months may elapse before these heal, and often very severe measures have to be resorted to, not unfrequently with indifferent success. Buboes have even been pricked on the summit with a needle to evacuate the pus, but in the cases $I$ have seen treated in this way, the opening remained a small, sharp-edged, circular hole, while beneath the skin, the suppuration went on unchecked till a larger opening was made by nature or by the surgeon.

Had such an opening been made in the lowest part of the swelling, it would have been a considerable improvement on the old plan, as here the pus would have drained away as it formed, and thus the destructive effects which result from its being confined might have been avoided. But the most prominent part, where the skin was thinnest, was selected, so that though the tension was relieved, the bubo soon filled again with pus, which pressed on the cellular tissue on all sides, and burrowed far and wide. If an attempt were made with a common needle to open the bubo at its lowest part, either no pus would be got away, or else a wound be left incapable of healing by the first intention. In an abscess seated in parts where no dependent position can be obtained, it would be of no use.

In some constitutions the results of the pus being confined are perfectly frightful. I suppose every surgeon has seen instances of buboes attaining an enormous size from this cause. Mr. Johnson has given three cases, showing how replete with danger this state of matters is.

In one case, in which gonorrhcea was the exciting cause, the rectum was laid open, and an extensive chain of disease stretched from the groin to the anus. After two years of frightful suffering, the patient died " in a state of raving delirium, and deplorable bodily attenuation and exhaustion." In the second case, that of a girl, in which the patient ultimately sank, examination after death revealed the rectum "absolutely insulated in a lake of pus." In the third, after many months of previous suffering, the patient was only freed from this troublesome malady by three months of absolute rest, laying open all the sinuses, and the most watchful care. Now this picture is not overdrawn, for I could fill whole pages with similar accounts given by different authors.

Exposing the suppurating cavity to the air may lead to the most serious consequences, and compromise the patient's safety. Uncontrollable phagedænic ulceration may set in, and rapidly endanger, if not destroy life; and a great number of cases have occurred in which the bubo has not merely refused to heal, but has taken on a slow and most intractable form of ulceration, lasting for months and even years: defying the most patient care and skill, and spreading to such a width and depth as to disfigure the patient for life, or even in the long run, to deprive him of life itself.

Nor is this picture drawn from the practice of a by-gone day. Not very long ago, Mr. Lloyd was obliged to tie the external iliac artery in a case of ulceration from bubo. The operation was performed after the destructive process had gone on for four months, and had several times placed the patient's life in danger. Secondary hæmorrhage also occurred five weeks after the operation.

A very similar case occurred about the same time in $\mathbf{M r}$. Simon's practice; ulceration, from a sinus being opened, spread so as to lay bare the femoral artery. So urgent was the danger of fatal hæmorrhage coning on, that "for a fortnight uninterrupted watch was kept at his side, the bed-clothes being so arranged as to leave his groin exposed." The artery did not give way, and the patient recovered.

One of the most alarming features of such a case is, that no beacon exists to warn the surgeon when a bubo will not bear opening. These, like other instances of phagedænic ulceration, often arise when least expected; and although they may in part be traced to definite causes, as the exhibition of mercury, sojourn in a foul ward, bad diet, \&c, yet it appears beyond doubt that a constitutional taint is a necessary element. Buboes are constantly opened or bursting in shattered, unhealthy-looking persons, some of them on the verge of mercurial erethism, without phagedæna setting in, while it often 